\title{
Thrombin-Induced Platelet Secretion
}

\author{
FURTHER EVIDENCE FOR A SPECIFIC PATHWAY
}

\author{
M. A. Shuman, M. Botney, and J. W. Fenton, II, Division of Hematology, \\ The Department of Medicine and the Cancer Research Institute, University of \\ California, San Francisco, California 94143; and Division of Laboratories and \\ Research, New York Department of Health, Albany, New York 12201
}

A в STRACT We have studied the interaction between thrombin and washed, human platelets using prostacyclin, a reversible inhibitor of platelet secretion. The effect of thrombin is limited to those reactions that are not inhibited by an increased concentration of platelet cyclic adenosine $3^{\prime}, 5^{\prime}$-monophosphate, because prostacyclin is a potent inducer of the latter. Prostacyclin-treated platelets were briefly (15-30 s) exposed to low concentrations of human thrombin (0.01-0.2 $\mathrm{U} / \mathrm{ml}$ ). After removal of the prostacyclin and thrombin, the platelets were incubated with fresh thrombin. Although they had not undergone the release reaction after the first thrombin incubation, these platelets had a diminished capacity to secrete $\left[{ }^{3} \mathrm{H}\right]$ serotonin when exposed to thrombin the second time. Refractoriness was concentration dependent: the higher the initial thrombin concentration, the greater the degree of inhibition of serotonin secretion on subsequent thrombin exposure. Inhibition was closely related to the ability of thrombin to induce platelet secretion and not to its esterase or fibrinogen clotting activity. Diisopropyl fluorophosphate-inactive thrombin did not induce refractoriness. Refractoriness to thrombin did not increase when the time of the initial incubation with thrombin was lengthened, nor was it reversible.

Inhibition was thrombin specific: serotonin secretion induced by collagen, wheat germ agglutinin, and the ionophore A23187 was minimally affected. For an equivalent amount of thrombin bound, a decrease was observed in serotonin secretion by thrombin-pretreated platelets compared to control platelets. Thus, there is at least one step in the secretory pathway between thrombin binding and regulation of adenylate cyclase. This step appears to transmit the signal that leads to extrusion of intracellular granular contents.

A preliminary report of this work was presented at the Annual Meeting of the American Federation for Clinical Research, San Francisco, Calif., 1978, and was published in abstract form in Clin. Res. 26: 357A. (Abstr.)

Received for publication 27 October 1978 and in revised form 26 January 1979.

\section{INTRODUCTION}

Thrombin, a blood coagulation factor with proteinase activity, is also capable of initiating platelet secretion (1). Because it stimulates platelet secretion at concentrations that are generated physiologically (1-2 $\mathrm{nM}$ ), it is likely to be important in the initiation of the platelet thrombus formed in response to vascular injury $(2,3)$. The mechanism by which thrombin stimulates platelet secretion is unknown. Recent evidence suggests that thrombin initiates the platelet release reaction ${ }^{1}$ through a different pathway from that of other mediators of secretion $(4,5)$. Most agents known to induce secretion require formation of platelet prostaglandin endoperoxides and release of adenosine diphosphate. Thrombin, however, does not.

Equilibrium binding of thrombin to the platelet surface appears to be the first step in this pathway (6-10). Thrombin binding is specific, saturable, and reversible (9). The precise correlation that has been demonstrated between the amount of thrombin bound to the platelet and the extent of secretion suggests that binding may be of physiological importance (11). However, although it may be the necessary first step in the secretory pathway, binding in itself is insufficient to induce the release reaction. This is indicated by the fact that thrombin inactivated at its serine center and native thrombin bind identically to platelets, whereas only the native form induces secretion $(7,12)$.

The specific reactions that follow thrombin binding have not been characterized. Although thrombin stimulates a variety of metabolic changes in platelets (1316), these reactions occur in response to most agonists that stimulate the release reaction. One reason for the paucity of information on the sequence of events that takes place after thrombin binding is the rapidity with which secretion occurs. Because in human platelets secretion takes place in $<1 \mathrm{~min}(17)$, it has been dif-

${ }^{1}$ The term "release reaction" refers to platelet secretion and the terms are used interchangeably. 
ficult to separate the unique effects of thrombin on platelets from the general changes associated with secretion. By incubating platelets with prostacyclin $\left(\mathrm{PGI}_{2}\right),{ }^{2}$ a reversible inhibitor of secretion, we have been able to study the presecretory effects of thrombin on platelets. In this report, we describe the nature of some of these effects and how they relate to subsequent platelet secretion.

\section{METHODS}

Preparation of platelets, thrombin, and other materials. Platelets were prepared from freshly drawn blood according to the method of Baenziger and Majerus (18).

Human alpha and gamma thrombin were prepared as described previously $(11,19,20)$. The specific activities were 2,400-4,000 and $1.88 \mathrm{U} / \mathrm{mg}$, respectively.

Thrombin $(0.022 \mathrm{mg})$ was incubated for $1-2 \mathrm{~min}$ at $20^{\circ} \mathrm{C}$ with 0.038 U lactoperoxidase (Sigma Chemical Co., St. Louis, Mo.), $0.062 \mathrm{U}$ glucose oxidase (Type V, Sigma Chemical Co.), $0.18 \% \beta-d$ glucose, $0.75 \mathrm{mCi}\left[{ }^{125} \mathrm{I}\right]$ sodium iodide (New England Nuclear, Boston, Mass.), $0.01 \mathrm{M}$ benzamidine, and buffer $(0.2 \mathrm{M} \mathrm{NaCl}-0.05 \mathrm{M}$ sodium phosphate, $\mathrm{pH} \mathrm{7.0)}$ in a total volume of $0.5 \mathrm{ml}$. [ $\left.{ }^{125} \mathrm{I}\right] \mathrm{Thrombin}$ was separated from [ $\left.{ }^{125} \mathrm{I}\right] \mathrm{so}-$ dium iodide by gel filtration.

Thrombin was incubated for $30 \mathrm{~min}$ at $20^{\circ} \mathrm{C}$ in $0.75 \mathrm{M} \mathrm{NaCl}-$ $0.025 \mathrm{M}$ imidiazole, $\mathrm{pH} 7.3$, with diisopropyl fluorophosphate (iPr $\mathrm{P}_{2} \mathrm{PF}$ ) diluted 1:100 to a final concentration of $0.01 \mathrm{M}$ to prepare diisopropylphosphoryl thrombin (DIP-thrombin). The $\mathrm{iPr}_{2} \mathrm{PF}$ was removed by chromatography over a column of Sephadex G-25-80 (Pharmacia Fine Chemicals Inc., Piscataway, N. J.). The DIP-thrombin had no demonstrable clotting activity.

Both the $\left[{ }^{125} \mathrm{I}\right]$ thrombin and DIP-thrombin were stored at $-70^{\circ} \mathrm{C}$. The [ $\left.{ }^{125} \mathrm{I}\right]$ thrombin was used the same day of preparation and the DIP-thrombin over a period of $3 \mathrm{wk}$. Acid soluble collagen was a gift from Mr. Heinz Scheuenstuhl. It was prepared from bovine achilles tendon, Type 1, purchased from Sigma Chemical Co. Wheat germ lectin was prepared by affinity chromatography using ovamucoid-Sepharose (Pharmacia Fine Chemicals Inc.) as described by LeVine et al. (21). $\mathrm{PGI}_{2}$ was synthesized by $\mathrm{K}$. C. Nicolau of the University of Pennsylvania (22), and kindly supplied by Dr. J. Bryan Smith of Thomas Jefferson University, Philadelphia, Pa. Rabbit antihuman thrombin antibody and $F\left(a^{\prime}\right)_{2}$ fragments were prepared as described previously (8).

Preincubation of platelets with thrombin. Platelets (2-4 $\times 10^{9} / \mathrm{ml}$ ) prelabeled with $\left[{ }^{3} \mathrm{H}\right]$ serotonin $(7)$, were suspended in $0.5 \mathrm{ml}$ of buffer containing $0.14 \mathrm{M} \mathrm{NaCl}, 0.015 \mathrm{M} \mathrm{Na}_{2} \mathrm{HPO}_{4}$ $\mathrm{NaH}_{2} \mathrm{PO}_{4}, 0.005 \mathrm{M}$ glucose, $0.5 \%$ bovine serum albumin (fraction 1, Sigma Chemical Co.), $0.002 \mathrm{M}$ EDTA, and $2 \mu \mathrm{M}$ imipramine (Sigma Chemical Co.), pH 7.4. $\mathrm{PGI}_{2}(20 \mathrm{nM}$ final concentration) was added in a 1:100 dilution for $1 \mathrm{~min}$ before the addition of thrombin (0.01-0.2 U/ml). Platelets and thrombin were incubated at room temperature for 15-30 s, then anti-thrombin $\mathrm{F}\left(\mathrm{ab}^{\prime}\right)_{2}$ fragments were added in a concentration that completely inactivated the thrombin within $30 \mathrm{~s}$. Platelets were then centrifuged at 12,000 rpm for $2 \mathrm{~min}$ in a Beckman Microfuge B (Beckman Instruments, Inc., Spinco Div., Palo Alto, Calif.). The supernate was collected and the radioactivity counted to determine the extent of secretion of $\left[{ }^{3} \mathrm{H}\right]$ serotonin.

${ }^{2}$ Abbreviations used in this paper: cyclic AMP, cyclic adenosine 3 ',5'-monophosphate; $\mathrm{iPr}_{2} \mathrm{PF}$, diisopropyl fluorophosphate; DIP-thrombin, diisopropylphosphoryl thrombin; $\mathrm{PGI}_{2}$, prostacyclin; $\mathrm{PGE}_{1}$, prostaglandin $\mathrm{E}_{1}$.
The platelet pellet was resuspended in isotonic buffer $(0.14 \mathrm{M}$ $\mathrm{NaCl}, 0.015 \mathrm{M} \mathrm{Na}_{2} \mathrm{HPO}_{4} / \mathrm{NaH}_{2} \mathrm{PO}_{4}, 0.005 \mathrm{M}$ glucose, pH 7.4). The platelet concentration was then determined with a hematocytometer (23).

Samples of platelets $\left(5 \times 10^{7}\right)$, previously exposed to alpha thrombin (or its derivatives, DIP- or gamma thrombin), were suspended in $0.5 \mathrm{ml}$ of the isotonic phosphate buffer, pH 7.4. Controls were treated identically except for preincubation with thrombin. A second release inducing agent was added (thrombin, collagen, wheat germ lectin, or the ionophore A23187). Platelets were collected by membrane filtration and the extent of secretion determined by the amount of $\left[{ }^{3} \mathrm{H}\right]$ serotonin retained by the platelets (7). The time from removal of $\mathrm{PGI}_{2}$ to addition of the second agent varied 15-30 min.

Correlation of binding of $\left[{ }^{125} I\right]$ thrombin to platelets with the release of $\left[{ }^{3} \mathrm{H}\right]$ serotonin. $\left[{ }^{125} \mathrm{I}\right] \mathrm{Th}$ rombin, 0.013-1.025 $\mathrm{U}$, was added to $1 \times 10^{8}$ platelets prelabeled with $\left[{ }^{3} \mathrm{H}\right]$ serotonin in a total volume of $0.65 \mathrm{ml}$ of buffer: $0.14 \mathrm{M}$ sodium chloride, $0.015 \mathrm{M}$ Tris- $\mathrm{HCl}, 0.0055 \mathrm{M}$ glucose, and $0.5 \%$ fat-free albumin (Sigma Chemical Co.), pH 7.4. After incubation for $5 \mathrm{~min}$ at $22^{\circ} \mathrm{C}$, aliquots were removed and thrombin binding or serotonin release measured simultaneously.

Thrombin binding. Platelets $(0.4 \mathrm{ml})$ were centrifuged through a mixture of $n$-butyl phthalate and type A Apiezon oil (James G. Biddle Co., Plymouth Meeting, Pa.), and the radioactivity contained in the platelet pellet determined in a gamma scintillation spectrometer (24). Net thrombin bound and nonspecific binding were determined as described previously (7).

Platelet secretion. Platelets $(0.2 \mathrm{ml})$ were membrane filtered and the retained $\left[{ }^{3} \mathrm{H}\right]$ serotonin was measured in a liquid scintillation counter. Gross counts per minute were corrected for ${ }^{125}$ I using ${ }^{125}$ I standards which were counted by beta and gamma scintillation spectrometry (11).

\section{RESULTS}

Inhibition of thrombin-induced platelet secretion of $\left[{ }^{3} \mathrm{H}\right]$ serotonin by $\mathrm{PGI}_{2}$. To determine the effects of thrombin on platelets apart from those changes associated with the release reaction, it was necessary to develop a technique by which platelets could be incubated with thrombin without subsequent secretion. Furthermore, it was required that the inhibition be reversible so that platelet responsiveness could be studied after the removal of thrombin. $\mathrm{PGI}_{2}$, an inhibitor of platelet aggregation (25), appeared to be a likely agent because its effects are rapidly reversible $(26,27)$.

Platelets incubated for 1 min with $20 \mathrm{nM} \mathrm{PGI}_{2}$ did not secrete $\left[{ }^{3} \mathrm{H}\right]$ serotonin when exposed to thrombin concentrations that would normally induce $10-60 \%$ secretion (Fig. 1). In addition, we determined that once $\mathrm{PGI}_{2}$-induced inhibition was reversed, the platelets responded normally to thrombin (data not shown).

Effect of preincubating platelets with thrombin on their secretory response to subsequent thrombin stimulation. As shown in Fig. 2, when $\mathrm{PGI}_{2}$-treated platelets were briefly exposed to low concentrations of thrombin, centrifuged to remove both the $\mathrm{PGI}_{2}$ and thrombin, then resuspended in buffer, there was inhibition of $\left[{ }^{3} \mathrm{H}\right]$ serotonin secretion upon reexposure of the platelets to thrombin. The extent of inhibition was 


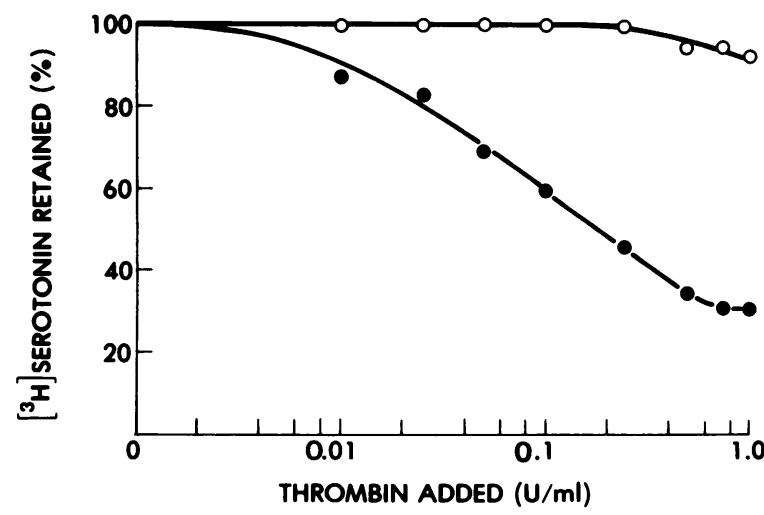

FIGURE 1 Inhibition of thrombin-induced platelet secretion of $\left[{ }^{3} \mathrm{H}\right]$ serotonin by $\mathrm{PGI}_{2}$. Washed platelets $\left(5 \times 10^{7}\right)$ prelabeled with $\left[{ }^{3} \mathrm{H}\right]$ serotonin were suspended in $0.5 \mathrm{ml}$ of buffer containing $0.14 \mathrm{M}$ sodium chloride, $0.015 \mathrm{M}$ sodium phosphate, $0.005 \mathrm{M}$ glucose, $0.5 \%$ bovine serum albumin, $0.002 \mathrm{M}$ EDTA, and $2 \mu \mathrm{M}$ imipramine, $\mathrm{pH}$ 7.4. Either $\mathrm{PGI}_{2}$ diluted in ethanol (final concentration, $20 \mathrm{nM}$ ) or an equivalent volume of ethanol (control) was added $1 \mathrm{~min}$ before the addition of thrombin. After incubation for 15-30 s at room temperature, the extent of secretion of $\left[{ }^{3} \mathrm{H}\right]$ serotonin was determined by membrane filtration (7). Secretion is expressed as the percentage of serotonin retained compared to control incubations without thrombin. $\bigcirc$, prostacyclin-treated platelets; $\bullet$, control platelets.

dependent on the initial thrombin concentration (Fig. 2). Complete inhibition of release of $\left[{ }^{3} \mathrm{H}\right]$ serotonin was observed when $\mathrm{PGI}_{2}$-treated platelets were preincubated with $0.1 \mathrm{U} / \mathrm{ml}$ of thrombin, a concentration which would otherwise induce $\cong 50 \%\left[{ }^{3} \mathrm{H}\right]$ serotonin secretion.

That this effect was not due to centrifugation of the platelets or to the $\mathrm{PGI}_{2}$ was indicated by the fact that control platelets were treated identically except for the initial exposure to thrombin. Similarly, inhibition did not result from platelet secretion after the first thrombin incubation, because $<1 \%$ of the $\left[{ }^{3} \mathrm{H}\right]$ serotonin appeared in the supernate after centrifugation. Imipramine was included in the initial incubation mixture to block reuptake of $\left[{ }^{3} \mathrm{H}\right]$ serotonin (28). Anti-thrombin $\mathrm{F}\left(\mathrm{ab}^{\prime}\right)_{2}$ fragments were added to the platelets $15 \mathrm{~s}$ after the thrombin to limit the duration of its effect. When thrombin was preincubated with anti-thrombin $\mathrm{F}\left(\mathrm{ab}^{\prime}\right)_{2}$ fragments for $30 \mathrm{~s}$ before its addition to platelets, a $90 \%$ decrease in its inhibitory effect on subsequent platelet secretion was seen.

It is interesting that platelets preincubated with $\mathrm{PGI}_{2}$ before thrombin exposure did not secrete $\left[{ }^{3} \mathrm{H}\right]$ serotonin once the effect of $\mathrm{PGI}_{2}$ had been reversed and the thrombin removed. It should be noted also that the incubation period with thrombin (15-30 s) was limited to the time necessary for thrombin-induced platelet secretion (17). Thus, although thrombin binding was normal in the presence of $\mathrm{PGI}_{2}$ (data not shown), after binding, the secretory stimulus did not progress to a point that resulted in the release reaction once $\mathrm{PGI}_{2}$ inhibition was reversed.

Effect of modification of native thrombin on its reaction with $P G I_{2}$-treated platelets. Next, we used modified thrombins to determine the relationship between their ability to induce platelet secretion and their effect on $\mathrm{PGI}_{2}$-treated platelets. Platelets were preincubated with $\mathrm{PGI}_{2}$, then with thrombin inactivated at its serine-active site with i $_{2} \mathrm{PF}$ (DIP-thrombin). Thrombin modified in this way binds to platelets identically to native thrombin but does not cause the release reaction (7). As shown in Fig. 3, there was no difference in the subsequent secretion of $\left[{ }^{3} \mathrm{H}\right]$ serotonin induced by native thrombin compared to platelets not preincubated with DIP-thrombin. On the other hand, there was complete inhibition of serotonin secretion in platelets preincubated with an equivalent molar concentration of native thromin (Fig. 3). These results suggest that to induce refractoriness, thrombin must have the capability to initiate secretion.

Because DIP-thrombin and native thrombin bind to the same site on the platelet, we examined the possibility that an excess of DIP-thrombin would prevent the inhibition induced by native thrombin. Platelets were incubated for $10 \mathrm{~min}$ first with DIP-thrombin then for $15 \mathrm{~s}$ with $1 / 10$ as much native thrombin. As shown in

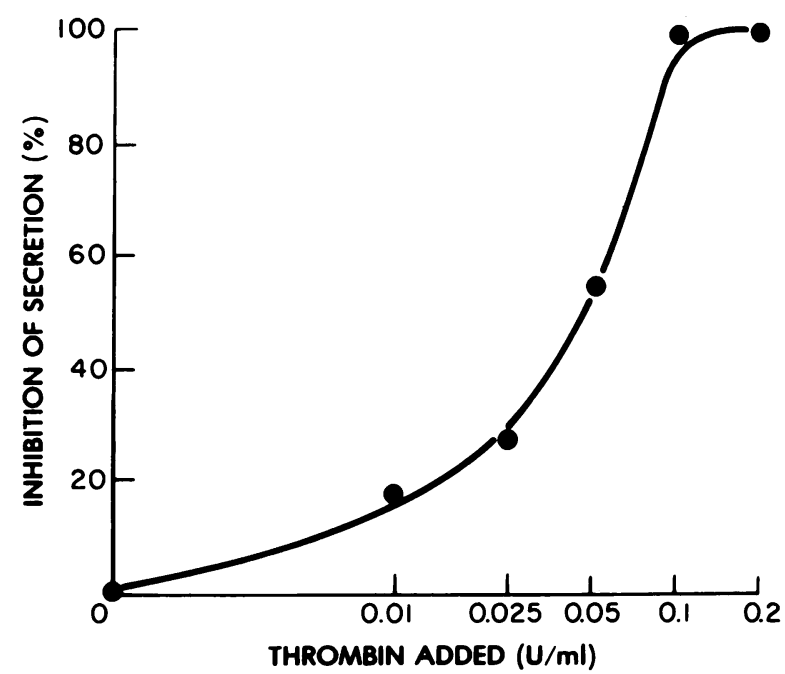

FIGURE 2 Effect of preincubating platelets with thrombin on their secretory response to subsequent thrombin stimulation. Thrombin (0.01-0.2 U/ml) or buffer (control) was added to platelets which were then centrifuged and resuspended in fresh buffer as described in Methods. Aliquots of $5 \times 10^{7}$ platelets were removed, incubated with $0.2 \mathrm{U} / \mathrm{ml}$ of thrombin, and secretion of $\left[{ }^{3} \mathrm{H}\right]$ serotonin was determined by membrane filtration. Inhibition of secretion was calculated from the formula: ([\% $\left[{ }^{3} \mathrm{H}\right]$ serotonin secreted, control platelets - \% $\left[{ }^{3} \mathrm{H}\right]$ serotonin secreted, thrombin-pretreated platelets $]$ $\left[\%\left[{ }^{3} \mathrm{H}\right]\right.$ serotonin secreted, control platelets $\left.]\right) \times 100$. 


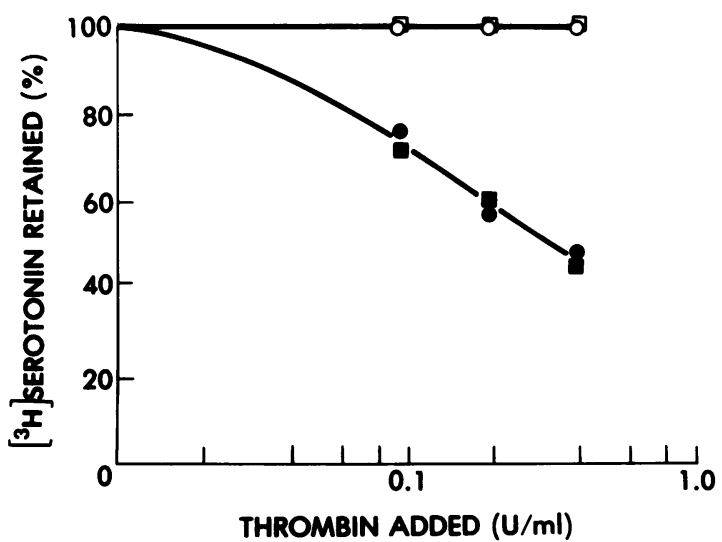

FIGURE 3 Effect of preincubating platelets with DIP-thrombin on their subsequent response to native thrombin. $\mathrm{PGI}_{2}$ treated platelets were preincubated with either $0.196 \mathrm{U} / \mathrm{ml}$ DIP thrombin ( $) ; 0.196 \mathrm{U} / \mathrm{ml}$ native thrombin $(O) ; 1.96 \mathrm{U} /$ $\mathrm{ml} \mathrm{DIP-thrombin} \mathrm{for} 10 \mathrm{~min}$; then $0.196 \mathrm{U} / \mathrm{ml}$ native thrombin ( $\square$ ); or buffer (O); for $15-30 \mathrm{~s}$; then centrifuged and resuspended as described in Fig. 2. Thrombin (0.1-0.4 U/ml) was added to aliquots of $5 \times 10^{7}$ platelets for $30 \mathrm{~s}$ and secretion of $\left[{ }^{3} \mathrm{H}\right]$ serotonin determined by membrane filtration.

Fig. 3, DIP-thrombin did not alter the subsequent inhibition of platelet secretion by native thrombin. The explanation for this is unclear, but it should be noted that DIP-thrombin does not block thrombin-induced platelet secretion either (7).

Gamma thrombin, a product of limited tryptic proteolysis of alpha thrombin, has $\cong 0.1 \%$ of the fibrinogen clotting activity of native thrombin, $1 \%$ of the platelet release-inducing activity, and full esterase activity $(5$, $20)$. When either alpha or gamma thrombin was prein- cubated with $\mathrm{PGI}_{2}$-treated platelets at equivalent concentrations based on the ability to induce platelet secretion, there was complete inhibition of secretion on reexposure to thrombin (Table I). The platelets were preincubated with a concentration of alpha or gamma thrombin sufficient to give $50 \%$ secretion of $\left[{ }^{3} \mathrm{H}\right]$ serotonin in the absence of $\mathrm{PGI}_{2}$. On a molar basis the concentration of gamma thrombin was 75 -fold higher than the alpha thrombin and had only $2 \%$ of the clotting activity. Apparently the inhibition of secretion that resulted from thrombin preincubation was specifically related to its ability to induce secretion and not to its esterase activity. Nor does it appear to be a nonspecific proteolytic effect, because an equivalent inhibitory effect was seen at a 50-fold lower concentration based on the ability to cleave fibrinogen.

Effect of increasing the thrombin concentration on platelet secretion inhibited by prior incubation with thrombin. Next, we determined whether the platelet refractoriness to thrombin could be overcome by increasing the thrombin concentration with which the platelets were stimulated the second time. As shown in Fig. 4, a fourfold higher concentration of thrombin was required to achieve the same extent of serotonin secretion $(50 \%)$ as for platelets not previously exposed to thrombin. When the time of preincubation of platelets with thrombin was increased from 15-30 to $300 \mathrm{~s}$, no additional increase in the concentration of thrombin was necessary to achieve secretion (Fig. 4). The same result was obtained when a concentration of thrombin that resulted in $50 \%$ inhibition of secretion was used. There was no increase in the percentage of inhibition when the preincubation was lengthened to $300 \mathrm{~s}$.

TABLE I

Effect of Preincubation of Platelets with Alpha or Gamma Thrombin on Subsequent Thrombin-Induced Platelet Secretion

\begin{tabular}{|c|c|c|c|c|}
\hline & $\begin{array}{l}\text { Thrombin concentration } \\
\text { used in preincubation }\end{array}$ & $\begin{array}{l}\text { Clotting } \\
\text { activity }\end{array}$ & $\begin{array}{l}\text { Release of platelet } \\
{\left[{ }^{3} \mathrm{H}\right] \text { serotonin }} \\
\text { control platelets* }\end{array}$ & $\begin{array}{c}\text { Inhibition of } \\
\text { platelet secretion }\end{array}$ \\
\hline & $\mu g / m l$ & U/ml & & \\
\hline \multicolumn{5}{|l|}{ Alpha thrombin } \\
\hline Experiment 1 & 0.042 & 0.192 & 50 & 100 \\
\hline Experiment 2 & 0.042 & 0.192 & 57 & 100 \\
\hline \multicolumn{5}{|l|}{ Gamma thrombin } \\
\hline Experiment 1 & 1.0 & 0.039 & 50 & 100 \\
\hline Experiment 2 & 0.5 & 0.020 & 21 & 64 \\
\hline
\end{tabular}

Platelets prelabeled with $\left[{ }^{3} \mathrm{H}\right]$ serotonin were incubated first with $\mathrm{PGI}_{2}(25 \mathrm{nM})$, then either alpha or gamma thrombin, or buffer (control) for 15-30 s. After centrifugation and resuspension in fresh buffer, $0.192 \mathrm{U} / \mathrm{ml}$ of alpha thrombin was added to the platelets and the extent of $\left[{ }^{3} \mathrm{H}\right]$ serotonin secretion determined. Calculation of inhibition of platelet secretion of $\left[{ }^{3} \mathrm{H}\right]$ serotonin was determined as described in Fig. 2.

* The release-inducing activity of thrombin was determined in a parallel experiment with platelets not pretreated with $\mathrm{PGI}_{2}$. 


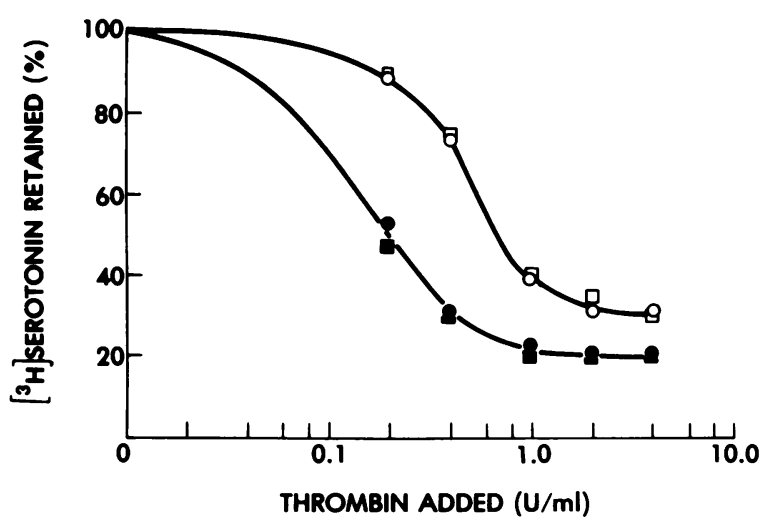

FIGURE 4 Effect of increasing thrombin concentrations on platelet refractoriness induced by prior incubation with thrombin. $\mathrm{PGI}_{2}$-treated platelets were preincubated with thrombin $(0.196 \mathrm{U} / \mathrm{ml})$ or buffer for $15-30$ or $300 \mathrm{~s}$, then centrifuged and resuspended in fresh buffer. Thrombin $(0.196-$ $4.0 \mathrm{U} / \mathrm{ml}$ ) was added to aliquots of $5 \times 10^{7}$ platelets for $15-30 \mathrm{~s}$ and secretion of $\left[{ }^{3} \mathrm{H}\right]$ serotonin was determined by membrane filtration. - control platelets, $15-30 \mathrm{~s}$; $\bigcirc$, platelets preincubated for $15-30 \mathrm{~s}$ with thrombin; $\mathbf{0}$, control platelets, $300 \mathrm{~s} ; \square$, platelets preincubated for $300 \mathrm{~s}$ with thrombin.

Specificity of inhibition of platelet secretion induced by thrombin preincubation. The effect of thrombin pretreatment on the release reaction induced by other agonists was studied also. When collagen, wheat germ agglutinin, or the calcium ionophore A23187 was used to stimulate platelet secretion, there was little difference in the extent of $\left[{ }^{3} \mathrm{H}\right]$ serotonin release whether or not the platelets were first preincubated with thrombin (Table II). The concentration of thrombin used, $0.19 \mathrm{U} /$ $\mathrm{ml}$, however, resulted in $90 \%$ inhibition of thrombininduced secretion. A small, but consistent, inhibition of A23187-induced secretion was seen on several occa-

TABLE II

Effect of Thrombin Pretreatment of Platelets on Subsequent Secretory Response

\begin{tabular}{lcc}
\hline \multirow{2}{*}{\multicolumn{1}{c}{ Stimulus }} & \multicolumn{2}{c}{$\left[{ }^{3} \mathrm{H}\right]$ Serotonin secreted } \\
\cline { 2 - 3 } & Control & Thrombin pretreated \\
\hline & \multicolumn{2}{c}{$\%$} \\
Thrombin $(0.2 \mathrm{U} / \mathrm{ml})$ & 53 & 5 \\
Collagen $(16 \mu \mathrm{g} / \mathrm{ml})$ & 17 & 21 \\
Collagen $(40 \mu \mathrm{g} / \mathrm{ml})$ & 34 & 28 \\
Wheat germ lectin $(300 \mu \mathrm{g} / \mathrm{ml})$ & 17 & 13 \\
A23187 $(4.0 \mu \mathrm{g} / \mathrm{ml})$ & 59 & 48 \\
\hline
\end{tabular}

$\mathrm{PGI}_{2}$-treated platelets were preincubated with $0.19 \mathrm{U} / \mathrm{ml}$ of thrombin or buffer for 15-30 s, then sedimented by centrifugation. After resuspension in fresh buffer, secretion of $\left[{ }^{3} \mathrm{H}\right]$ serotonin in response to the indicated agonist was determined. The results depicted are from one of four experiments, each of which gave similar results. sions. The significance of this is unknown. This marked refractoriness to thrombin but not other platelet stimuli suggests that the effect of thrombin preincubation is specific.

Binding of $\left[{ }^{125} I\right]$ thrombin to platelets previously exposed to thrombin. To determine whether the refactoriness of platelets to thrombin was because of an effect on thrombin binding, the following experiment was performed: Platelets were preincubated with a concentration of thrombin $(0.2 \mathrm{U} / \mathrm{ml})$ which resulted in 93\% inhibition of serotonin secretion (platelets not pretreated with thrombin showed $59 \%$ secretion; thrombin-pretreated platelets, $7 \%$ secretion). The thrombin was removed by centrifugation and both binding of $\left[{ }^{125} I\right]$ thrombin to the resuspended platelets and extent of serotonin secretion were measured. As shown in Fig. 5, for the same amount of thrombin bound, a marked decrease was seen in serotonin secretion in those platelets preexposed to thrombin compared to control platelets. Approximately four times as much bound thrombin was required for $40 \%$ serotonin secretion in thrombin-pretreated platelets. Thus, the inhibitory effect on platelet secretion that followed thrombin pretreatment was because of alteration of a step subsequent to thrombin binding to platelets.

Duration of inhibition of platelet secretion induced by thrombin preincubation. In many tissues, reversible desensitization to agonist stimulation has been observed (29). We examined the possibility that the inhibition of platelet secretion we had observed was related to a reversible desensitization of the platelets to thrombin. Platelets were preincubated with thrombin in the presence of $\mathrm{PGI}_{2}$. Then, thrombin was inactivated with anti-thrombin $\mathrm{F}\left(\mathrm{ab}^{\prime}\right)_{2}$ fragments, and both the thrombin and $\mathrm{PGI}_{2}$ were removed after centrifugation of the platelets. The resuspended plate-

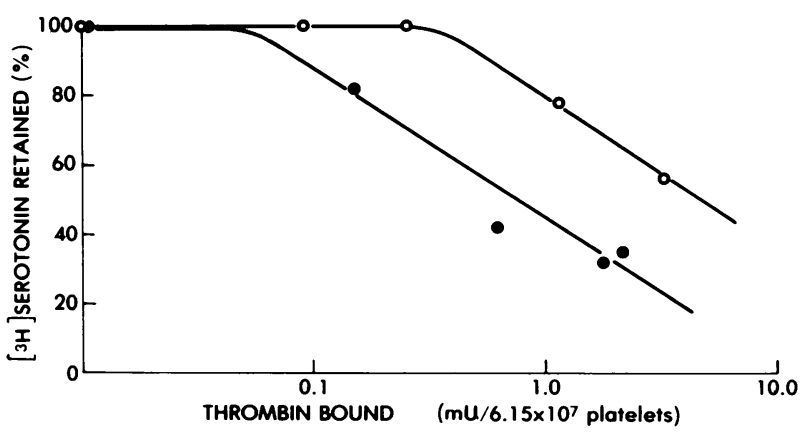

FIGURE 5 Effect of thrombin pretreatment of platelets on the relationship between thrombin binding and serotonin secretion. Platelets $\left(1 \times 10^{8}\right)$ previously treated with $0.2 \mathrm{U} / \mathrm{ml}$ of thrombin were incubated with $0.02-1.5 \mathrm{U} / \mathrm{ml}$ of $\left[{ }^{125} \mathrm{I}\right]$ thrombin. Then both the amount of $\left[{ }^{125} I\right]$ thrombin bound to the platelets and retained $\left[{ }^{3} \mathrm{H}\right]$ serotonin were determined on separate aliquots simultaneously. platelets preincubated with buffer; $\bigcirc$, platelets preincubated with thrombin. 
TABLE III

Effect of Time on the Reversibility of Platelet Refractoriness to Thrombin

\begin{tabular}{lrrrrr}
\hline & \multicolumn{4}{c}{$\left[{ }^{3} \mathrm{H}\right]$ Serotonin secreted } \\
\cline { 2 - 6 } Time, $\min \ldots \ldots \ldots \ldots \ldots \ldots \ldots \ldots \ldots$ & 45 & 100 & 150 & 210 \\
\hline & & & & \\
Control platelets & 59 & 38 & 40 & 50 \\
Thrombin-pretreated platelets & 5 & 4 & 8 & 0 \\
\hline
\end{tabular}

$\mathrm{PGI}_{2}$-treated platelets were preincubated with $0.192 \mathrm{U} / \mathrm{ml}$ of thrombin or buffer (control) for 15-30 s, sedimented by centrifugation, and resuspended in fresh buffer $(0.14 \mathrm{M} \mathrm{NaCl}$, $0.0154 \mathrm{M} \mathrm{Na} / \mathrm{PO}_{4}, 0.005 \mathrm{M}$ glucose, $0.0026 \mathrm{M} \mathrm{KCl}, 0.001 \mathrm{M}$ $\mathrm{MgCl}_{2}, 0.5 \%$ fat-free albumin, and $0.001 \mathrm{M}$ EDTA, $\mathrm{pH} 7.4$ ) as described in Methods. Aliquots were removed at the intervals indicated and $0.192 \mathrm{U} / \mathrm{ml}$ of thrombin added. Secretion of $\left[{ }^{3} \mathrm{H}\right]$ serotonin was determined by membrane filtration.

lets were then tested for thrombin-induced secretion of $\left[{ }^{3} \mathrm{H}\right]$ serotonin over a period of several hours. As indicated in Table III, inhibition was not diminished over a period of $3.5 \mathrm{~h}$. It would appear, therefore, that in the time period studied, the effect of thrombin preincubation on the platelets was irreversible.

\section{DISCUSSION}

Investigators have shown that once platelets have secreted in response to thrombin, their capacity to respond to thrombin a second time is diminished (30, $31)$. However, the step in the secretory pathway at which the platelets become modified has not been established. We have studied the interaction between $\mathrm{PGI}_{2}$-treated platelets and thrombin to determine the effects of thrombin on platelets before secretion. These platelets compared to those not prestimulated with thrombin exhibit a marked decrease in serotonin secretion. That refractoriness to thrombin stimulation is related to an alteration of a step in the secretory pathway rather than a nonphysiological effect is indicated by the following observations. First, the amount of thrombin used to induce refractoriness was not in excess of that necessary to induce secretion. Second, this effect was not due to prolonged exposure of the platelets to thrombin, because the incubation was limited to the time necessary to induce the release reaction. Third, the secretory and inhibitory effects of thrombin on platelets are both dose dependent. The higher the thrombin concentration, the greater the degree of secretion or inhibition. Fourth, the capacity of thrombin to render the platelets refractory correlates closely with its ability to induce secretion. This is indirect evidence that the inhibitory effect on the platelet is not secondary to a nonspecific esterolytic or proteolytic ac- tion of thrombin. Similarly, the marked discrepancy between the platelet-secretory and fibrinogen-clotting activity of the gamma thrombin suggests that inhibition is not the result of an alteration of platelet fibrinogen. Fifth, the effect was specific for thrombin: platelet secretion induced by wheat germ agglutinin, the ionophore A23187, and collagen was relatively unaffected by previous exposure of the platelets to thrombin. In addition, preincubation of $\mathrm{PGI}_{2}$-treated platelets with collagen has no effect on either thrombin- or collageninduced platelet secretion. ${ }^{3}$

We have demonstrated that platelet refractoriness to repeated thrombin stimulation is not a consequence of the release reaction or of subsequent events. Refractoriness does not appear to result from an alteration of thrombin binding, the first step in the secretory pathway, but instead from a decrease in its effectiveness in initiating secretion once it has bound to platelets. The observation that DIP-thrombin does not inhibit subsequent secretion induced by thrombin suggests that the inhibitory effect of native thrombin may be a consequence of limited proteolysis. Electrophoretic analysis of the membranes from platelets that have been exposed to thrombin in the presence of $\mathrm{PGI}_{2}$ should resolve this issue.

The diminished responsiveness of platelets to thrombin does not resemble the desensitization that has been observed in a variety of tissues in response to cholinergic or adrenergic agents, and drugs (29). The effect was seen after exposure of the platelets to thrombin for only 15-30 s. Although desensitization of parotid acinar cells to epinephrine after a 2 -min exposure has been described (32), a longer incubation period is generally required. Also, desensitization generally increases with time: the longer the exposure of target cells to the agonist, the greater the degree of refractoriness to subsequent stimulation. This is not the case with thrombin and platelets. As much inhibition was seen after $15 \mathrm{~s}$ of exposure to thrombin as after $300 \mathrm{~s}$. Also, inhibition was not reversed after the removal of thrombin and $\mathrm{PGI}_{2}$. Another difference between our findings and those of studies demonstrating desensitization is that frequently a correlation has been noted between desensitization and resensitization with a change in the number of receptors on the target cell. On the contrary, we observed that for the same amount of thrombin bound, there was less secretion in thrombin-pretreated platelets than control platelets. Thus, if refractoriness to thrombin is a result of desensitization, it differs in several respects from previously described examples.

Considerable evidence suggests that regulation of adenylate cyclase is an essential step in the platelet secretory pathway $(33,34)$. Most platelet agonists, in-

\footnotetext{
${ }^{3}$ Botney, M. B., A. L. Swanson, and M. A. Shuman. Manuscript in preparation.
} 
cluding thrombin, inhibit stimulation of adenylate cyclase (33-35). Conversely, agents such as $\mathrm{PGI}_{2}$, which cause an increase in cyclic adenosine $3^{\prime}, 5^{\prime}$ monophosphate (cyclic AMP), inhibit platelet secretion $(33,34)$. Reactions known to be inhibited by these secretory antagonists include hydrolysis of arachadonic acid from platelet phospholipid, and phosphorylation of platelet proteins in response to thrombin $(36,37)$. It is unlikely, therefore, that the refractoriness that results from the exposure of $\mathrm{PGI}_{2}$-treated platelets to thrombin is a result of an effect on either of these reactions or on events that occur subsequently.

Friedman and Detwiler have shown that cyclic A.MP inhibits thrombin-induced platelet secretion in a complex manner (38). On the basis of kinetic studies of ATP secretion, they concluded that both the rate of the initial steps in secretion and the total amount of secretion were inhibited by drugs that elevate cyclic AMP. At low concentrations of prostaglandin $\mathrm{E}_{1}\left(\mathrm{PGE}_{1}\right)$, there was both a delay in the onset of secretion and a prolongation in the time required for secretion, once initiated. At high $\mathrm{PGE}_{1}$ concentrations, complete inhibition of secretion occurred. Our observations suggest the presence of at least one step in the secretory pathway between thrombin binding and regulation of adenylate cyclase. This step appears to be specific for thrombin; it may also be an essential mechanism for transmitting the signal that leads to the extrusion of intracellular granular contents.

\section{ACKNOWLEDGMENTS}

We would like to thank Dr. Robert Hamill of the Lilly Research Laboratories (Eli Lilly and Company, Indianapolis, Ind.) for providing the ionophore A23187.

This work was supported by grants HL 21403 (Dr. Shuman) and HL 13160) (Dr. Fenton) from the National Institutes of Health.

\section{REFERENCES}

1. Grette, K. 1962. Studies on the mechanism of thrombincatalyzed hemostatic reactions in blood platelets. Acta Physiol. Scand. 56: 25-31.

2. Shuman, M. A., and P. W. Majerus. 1976. The measurement of thrombin in clotting blood by radioimmunoassay. J. Clin. Invest. 58: 1249-1258.

3. Shuman, M. A., and S. P. Levine. 1978. Thrombin generation and secretion of platelet Factor 4 during blood clotting. J. Clin. Invest. 61: 1102-1106.

4. Packham, M. A., M. A. Guccione, J. P. Greenberg, R. L. Kinlough-Rathbone, and J. F. Mustard. 1977. Release of ${ }^{14} \mathrm{C}$-serotonin during initial platelet changes induced by thrombin, collagen, or A23187. Blood. 50: 915-926.

5. Charo, I. F., R. D. Feinman, and T. C. Detwiler. 1977. Interrelations of platelet aggregation and secretion. $J$. Clin. Invest. 60: 866-873.

6. Ganguly, P. 1974. Binding of thrombin to human platelets. Nature (Lond.). 247: 306-307.

7. Tollefsen, D. M., J. R. Feagler, and P. IV. Majerus. 1974
The binding of thrombin to the surface of human platelets. J. Biol. Chem. 249: 2646-2651.

8. Shuman, M. A., D. M. Tollefsen, and P. W. Majerus. 1976. The binding of human and bovine thrombin to platelets. Blood. 47: 43-53.

9. Majerus, P. W., D. M. Tollefsen, and M. A. Shuman. 1976. The interaction of platelets with thrombin. In Platelets in Biology and Pathology. J. L. Gordon, editor. North Holland Publishing Co., Amsterdam. 241-260.

10. Martin, B. M., W. W. Wasiewski, J. W. Fenton, II, and T. C. Detwiler. 1976. Equilibrium binding of thrombin to platelets. Biochemistry. 15: 4886-4893.

11. Shuman, M. A., and P. W. Majerus. 1975. The perturbation of thrombin binding to human platelets by anions. J. Clin. Invest. 56: 945-950.

12. Davey, M. G., and E. F. Luscher. 1967. Actions of thrombin and other coagulant and proteolytic enzymes on blood platelets. Nature (Lond.). 216: 857-858.

13. Lewis, N., and P. W. Majerus. 1969. Lipid metabolism in human platelets II. De novo phospholipid synthesis and the effect of thrombin on the pattern of synthesis. J. Clin. Invest. 48: 2114-2123.

14. Warshaw, A. L., L. Laster, and N. R. Shulman. 1966. The stimulation by thrombin of glucose oxidation in human platelets. J. Clin. Invest. 45: 1923-1934.

15. Karpatkin, S. 1967. Studies on human platelet glycolysis. Effect of glucose, cyanide, insulin, citrate, and agglutination and contraction on platelet glycolysis. J. Clin. Invest. 46: $409-417$.

16. Bills, T. K., J. B. Smith, and M. J. Silver. 1976. Metabolism of ${ }^{14} \mathrm{C}$ arachadonic acid by human platelets. Biochim. Biophys. Acta. 424: 303-314.

17. Detwiler, T. C., and R. D. Feinman. 1973. Kinetics of the thrombin-induced release of calcium (II) by platelets. Biochemistry. 12: 282-287.

18. Baenziger, N. G., and P. W. Majerus. 1974. Isolation of human platelets and platelet surface membrane. Methods Enzymol. 31: 149-155.

19. Fenton, J. IV., II, M. J. Fasco, A. B. Stackrow, D. L. Aronson, A. M. Young, and J. S. Finlayson. 1977. Human thrombins. Production, evaluation, and properties of $\alpha$-thrombin. J. Biol. Chem. 252: 3587-3598.

20. Fenton, J. W., II, B. H. Landis, D. A. Walz, and J. S. Finlayson. 1977. Human thrombins. In Chemistry and Biology of Thrombin. R. L. Lundblad, J. W. Fenton, II, and K. G. Mann, editors. Ann Arbor Science Publishers, Inc., Ann Arbor, Mich. 43-70.

21. LeVine, D., M. J. Kaplan, and P. J. Greenaway. 1972. The purification and characterization of wheat-germ agglutinin. Biochem. J. 129: 847-856.

22. Nicolau, K. C., W. E. Bernette, B. P. Gasic, R. L. Magolda, W. J. Sipio, M. J. Silver, J. B. Smith, and C. M. Ingerman. 1977. Rapid and easy preparation of prostacyclin. Lancet. I: $1058-1059$.

23. Brecher, G., and E. P. Cronkite. 1950. Morphology and enumeration of human blood platelets. J. Appl. Physiol. 3: $36.5-377$.

24. Miletich, J. P., C. M. Jackson, and P. W. Majerus. 1978. Properties of the Factor Xa binding site on human platelets. J. Biol. Chem. 253: 6908-6916.

25. Gryglewski, R. J., S. Bunting, S. Moncada, R. J. Flower, and J. R. Viane. 1976. Arterial walls are protected against deposition of platelet thrombi by a substance (prostaglandin $\mathrm{X}$ ) which they make from prostaglandin endoperoxides. Prostaglandins. 12: 685-713.

26. Gorman, R. R., S. Bunting, and (). V. Miller. 1977. Modulation of human platelet adenylate cyclase by prostacyclin (PGX). Prostaglandins. 13: 377-388. 
27. Tateson, J. E., S. Moncada, and J. R. Vane. 1977. Effects of prostacyclin (PGX) on cyclic AMP concentrations in human platelets. Prostaglandins. 13: 389-397.

28. Pletscher, A. 1968. Metabolism, transfer and storage of 5hydroxytryptamine in blood platelets. $\mathrm{Br}$. J. Pharmacol. Chemother. 32: 1-16.

29. Mickey, J. V., R. Tate, D. Mulliken, and R. J. Lefkowitz. 1977. Regulation of adenylate cyclase-coupled beta adrenergic receptor binding sites by beta adrenergic catecholamines in vitro. Mol. Pharmacol. 12: 409-419.

30. Harbury, C. B., and S. L. Schrier. 1974. The effect of a partial release reaction on subsequent platelet function. J. Lab. Clin. Med. 83: 877-886.

31. Reimers, H. J., M. A. Packham, R. L. Kinlough-Rathbone, and J. F. Mustard. 1973. Effect of repeated treatment of rabbit platelets with low concentrations of thrombin on their function, metabolism and survival. Br. J. Haematol. 25: 675-689.

32. Strittmatter, W. J., J. N. Davis, and R. J. Lefkowitz. 1977. $\alpha$-Adrenergic receptors in rat parotid cells. II. Desensitization of receptor binding sites and potassium release. J. Biol. Chem. 252: 5478-5482.
33. Salzman, E. W. 1974. Prostaglandins, cyclic AMP, and platelet function. Thromb. Diath. Haemorrh. 60(Suppl.): 311-319.

34. Haslam, R. J., and A. Taylor. 1971. Role of cyclic $3^{\prime}, 5^{\prime}-$ adenosine monophosphate in platelet aggregation. In Round Table on Platelet Aggregation. J. Caen, editor. Masson et Cie Editeurs. Paris, France. 85-93.

35. Brodie, G. N., N. L. Baenziger, L. R. Chase, and P. W. Majerus. 1972. The effects of thrombin on adenyl cyclase activity and a membrane protein from human platelets. J. Clin. Invest. 51: 81-88.

36. Minkes, M., N. Stanford, M. M-Y. Chi, G. J. Roth, A. Raz, P. Needleman, and P. W. Majerus. 1977. Cyclic adenosine $3^{\prime}, 5^{\prime}$-monophosphate inhibits the availability of arachidonate to prostaglandin synthetase in human platelet suspensions. J. Clin. Invest. 59: 449-454.

37. Lyons, R. M., N. Stanford, P. W. Majerus. 1975. Thrombininduced protein phosphorylation in human platelets. J. Clin. Invest. 56: 924-936.

38. Friedman, F., and T. C. Detwiler. 1975. Stimulussecretion coupling in platelets. Effects of drugs on secretion of adenosine 5'-triphosphate. Biochemistry. 14: 1315-1320. 